\title{
Experimental modal analysis and finite element model updating for structural health monitoring of reinforced concrete radioactive waste packages
}

\author{
Jesús N. Eiras ${ }^{(*)}$, Cédric Payan, Sandrine Rakotonarivo, Vincent Garnier \\ Aix Marseille Univ, CNRS, Centrale Marseille, LMA, Marseille, France. \\ (*)eiras@lma.cnrs-mrs.fr
}

\section{Abstract}

This study envisages the use of modal analysis for monitoring the structural health of radioactive waste packages. To this end, the calibration of a numerical model that describes the dynamic behavior is a critical issue for the success in damage detection. In this study, experimental modal analysis was conducted on a radioactive waste package mockup. The container was tested under different boundary conditions. Then, the experimental modal analysis data was used to update finite element models that describe the observed behaviors. The latter consists in the formulation of an optimization problem that minimizes the differences between the experimental and the numerical data. A twostep methodology is proposed for finite element model updating. First, a full factorial design of experiments allowed estimation of a set of parameters of the numerical model that minimize a cost function. Second, a genetic algorithm was conducted, wherein the initial population of parameters was generated as a function of that set of parameters obtained in the previous step. This study serves as preliminary step towards the implementation of a structural health monitoring based on modal analysis. Specific aspects for the implementation of a modal-based structural health monitoring system in a radioactive waste repository are also summarized.

\section{Keywords}

Finite element model updating, experimental modal analysis, radioactive waste package, reinforced concrete, dynamic properties. 
Andra (the French National Radioactive Waste Management Agency) is designing a geological repository — project Cigéo: "Industrial Center for Geological Disposal”-, for disposal of long-lived high- and intermediate-level radioactive wastes. Detailed description of the Cigéo project can be consulted in [1]. In the particular case of long-lived intermediate-level waste, the use of reinforced concrete containers as a disposal package seems to be the preferred solution in many countries [2], [3]. The waste packages consist of i) a primary waste package in the form of metallic drums which contain the immobilized radioactive waste, and ii) a precast reinforced concrete container, which is designed to host the primary waste package. Reinforced concrete containers provide a physical protection to the primary waste package, and they can be produced in a shape that eases handling operations. Figure 1a shows a schematic of a radioactive waste package prototype and its constitutive parts. This type of waste package prototype is being considered in the Cigéo project. It is foreseen that the waste packages be stacked (up to three packages) and stored in an underground cell with sufficient capacity. Figure $1 \mathrm{~b}$ shows a schematic description of the radioactive waste packages stored in an underground repository cell.
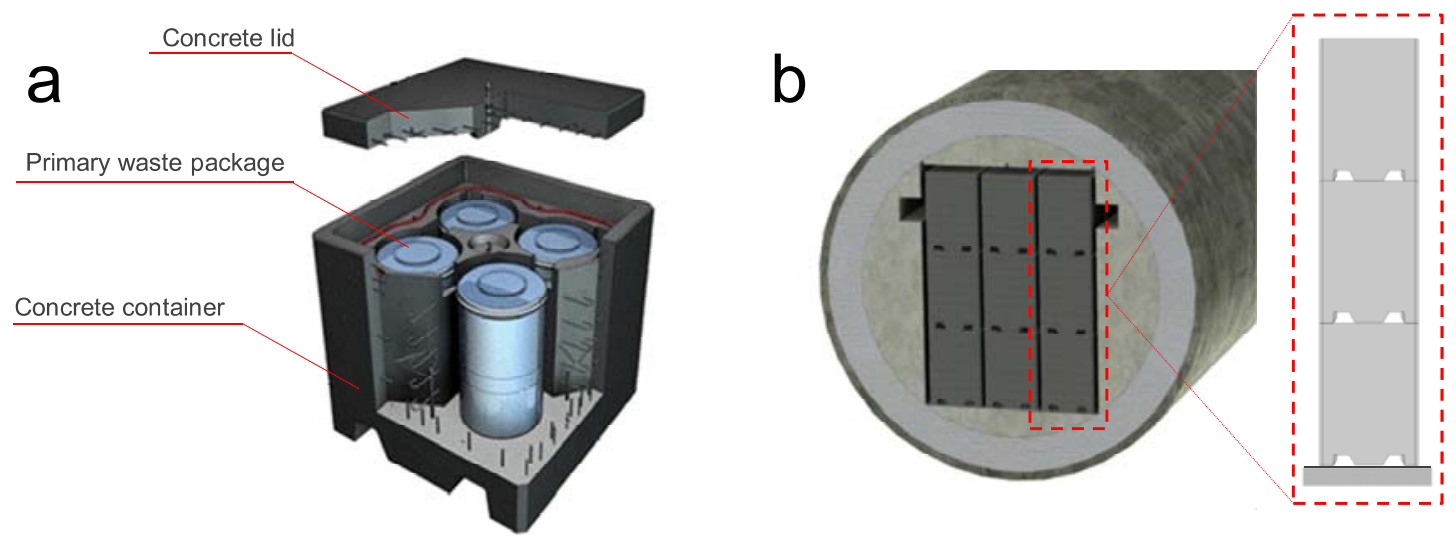

Figure 1. a) Typical reinforced concrete container designed to host intermediate and low level radioactive waste, and b) schematic description of the final disposition of waste packages in an underground repository cell, and detail of three stacked containers. 
The management and control of concrete in radioactive waste repositories entails several challenges. Despite concrete is being considered for radioactive waste disposal, there is no previous experience on concrete withstanding nuclear environments beyond its expected service life; $\sim 100$ years and at high temperatures $\left(\sim 65^{\circ} \mathrm{C}\right)$, for intermediate-level waste. A number of studies claim that further research on concrete durability is needed, to account for the simultaneous and synergistic actions of moisture, thermal, and mechanical loads along with radiation damage [3]-[8]. In addition, most of these studies also appeal to the need of developing nondestructive evaluation techniques and structural health monitoring (SHM) systems, that inform about the mechanical and durability performance of concrete in nuclear facilities. In particular, the difficulties arise from the limits on access to the structures and the harsh environment [3]. Previous studies investigated the feasibility of different nondestructive techniques, for the inspection of concrete in radioactive waste repositories. Iliopoulos and coworkers [9] combined the application of different nondestructive techniques on a radioactive waste container prototype subjected to high temperatures. Digital image correlation and acoustic emission were able to monitor the evolution of thermal induced cracking damage, while the depth of already formed cracks was successfully investigated through the ultrasonic pulse velocity. Davis and coworkers [10] applied different stress wave techniques aiming at periodic inspection of in-service radioactive waste tanks made of reinforced concrete. The investigated techniques included impulse response technique, ultrasonic pulse velocity and sonic logging. From this set of techniques, the authors were able to investigate the uniformity of concrete, and thus detect vulnerable zones. Andrade and coworkers [5], and Duffó and coworkers [6] have focused their researches in the application of electrical resistivity measurements, aiming at the service-life prediction of the steel reinforced concrete containers. In the particular case of the Cigéo project, Andra has instrumented prototype concrete containers with embedded optical fibers, so mechanical strains can be monitored since their production, and during their final disposition in the geological repository [11], [12].

This study envisages the use of modal analysis for monitoring the structural health of radioactive waste packages. In modal-based SHM applications, sensors are permanently installed in structures and continuously record their dynamic characteristics. Since dynamic properties are related to the mechanical integrity of structures, the eventual apparition of 
81 distress may be detected [13]. In turn, the modification of the dynamic properties because 82 of damage may also provide an indication of its severity and position within the structure. These contentions lay on the classification of damage assessment methodologies established by Rytter [14]: i) detect, ii) localize, iii) quantify, and lastly, iv) make a prognosis of remaining service life. Different approaches for detection and localization of damage from vibration responses have been reviewed in [15]-[17]. These approaches are classified as i) response-based methods, or ii) model-based methods. The former only depends on measured data, and is commonly used for damage identification, and eventually localization. The latter leverages an analytical or numerical model of the structure at the intact state, which is used to identify, localize, and in addition quantify the damage severity, by comparing an updated model at the damaged state [18]. Both approaches (responsebased and model-based) are complimentary, since in most practical cases, response-based methods are used to detect damage occurrence, while model-based damage are used to detect and quantify damage severity [18]. Furthermore, the success of model-based methods depends on the model quality. Very often, model assumptions, and errors in estimated model parameters (e.g. geometry, material properties, and boundary conditions) lead to significant discrepancy with regard to experimental data. In this respect, model updating techniques have become a subject of intense research. Model updating consists in the process of correcting the relative mismatch between experimental and numerical modelling data of a structure, for obtaining better agreement between both, and so improving the predictions of its dynamic and static mechanical behavior [19], [20]. This implies the formulation of an optimization problem wherein the differences between experimental and modelling data are minimized.

In civil engineering applications, modal analysis and finite element model (FEM) updating techniques have been applied and adapted for the evaluation and damage assessment of already existing structures [21], such as bridges [22], [23], footbridges [24], [25], buildings [25-27], dams [21], towers [28], [29], and cultural heritage [29], [30]. In this study, experimental modal analysis (EMA) and FEM updating was conducted on a radioactive waste container prototype. It was tested under different boundary conditions. First the radioactive waste package was tested empty. Second, after loading it with a dummy (non-radioactive) primary waste package. Such a dead load (the load of the primary 
112 waste package) affected the resonant frequencies of the concrete container. Then, different

113 finite element models that describe the loaded and unloaded concrete containers are 114 considered. The parameters of the finite element models are then adjusted to fit the EMA 115 data. Different algorithms and methodologies have been proposed to solve the optimization 116 problem [19], [31], being the nonlinear simplex algorithm [32], the trust-region algorithm 117 [27], neural networks [26], [28], [33], [34] and genetic algorithms [35] the most appealed 118 alternatives. In this study, a methodology for FEM updating is proposed, and applied on a 119 radioactive waste package. To do so, an initial global sensitivity analysis is conducted, 120 which is based on a full factorial design of experiments (DOE). This initial analysis allows 121 determination of the most influential FEM parameters on the cost function values, and 122 obtaining indicative values that minimize it. This indicative minimum solution is used to 123 narrow the space solution for solving the optimization problem through a genetic algorithm. 124 Finally, a local sensitivity analysis is conducted using a one-at-a-time approach. This 125 process analyzes the impact of the variations away from the attained optimum value for 126 every updating parameter. The updated numerical models may serve i) to predict the 127 mechanical performance of the waste packages under different loading scenarios, which 128 saves efforts and budget in cumbersome experiments, and ii) to obtain finite element 129 models for model-based detection techniques, as a baseline condition. To the authors' 130 knowledge, this is the first study that proposes modal analysis as an alternative to monitor 131 the mechanical performance of radioactive waste packages. This study constitutes a 132 preliminary analysis towards the implementation of a modal-based SHM system for 133 controlling the mechanical integrity of radioactive waste concrete containers. The 134 implementation of a modal-based SHM on a radioactive waste repository faces particular 135 challenges which are also summarized herein. These concerns are subject of ongoing 136 research.

In the following, the present article is structured as follows: Section 2 describes the waste package prototype, and provides a detailed description of the EMA test configuration. Section 3 describes the experimental results: the obtained resonant frequency 140 peaks and their corresponding modal shapes. Section 4 presents different finite element 141 models that describe the experimental data. Section 5 describes the optimization 142 methodology for finite element model updating, and analyzes the sensitivity of the finite 
143 element models to the input parameters. Finally, section 6 summarizes the conclusions that are drawn from this study, and summarizes practical aspects and challenges related to the implementation of a modal-based SHM strategy on a radioactive waste repository.

\section{Experimental details}

\subsection{Description of the radioactive waste package}

Figure 2a shows a schematic of the waste package and its parts: i) the primary waste package in the form of a metallic drum, and ii) a concrete container which is designed to host the primary waste package. A lid, also made of reinforced concrete, is fixed to the container through four partially threaded screws. The Figure $2 b$ shows the container dimensions. The container rests on four L-shaped feet (see Figure 2b). Overall, it measures $2.25 \mathrm{~m} \times 1.54 \mathrm{~m} \times 1.54 \mathrm{~m}$, and weights roughly 12 tons when it is loaded with the primary waste package. Table 1 lists indicative values of mass for the different parts.

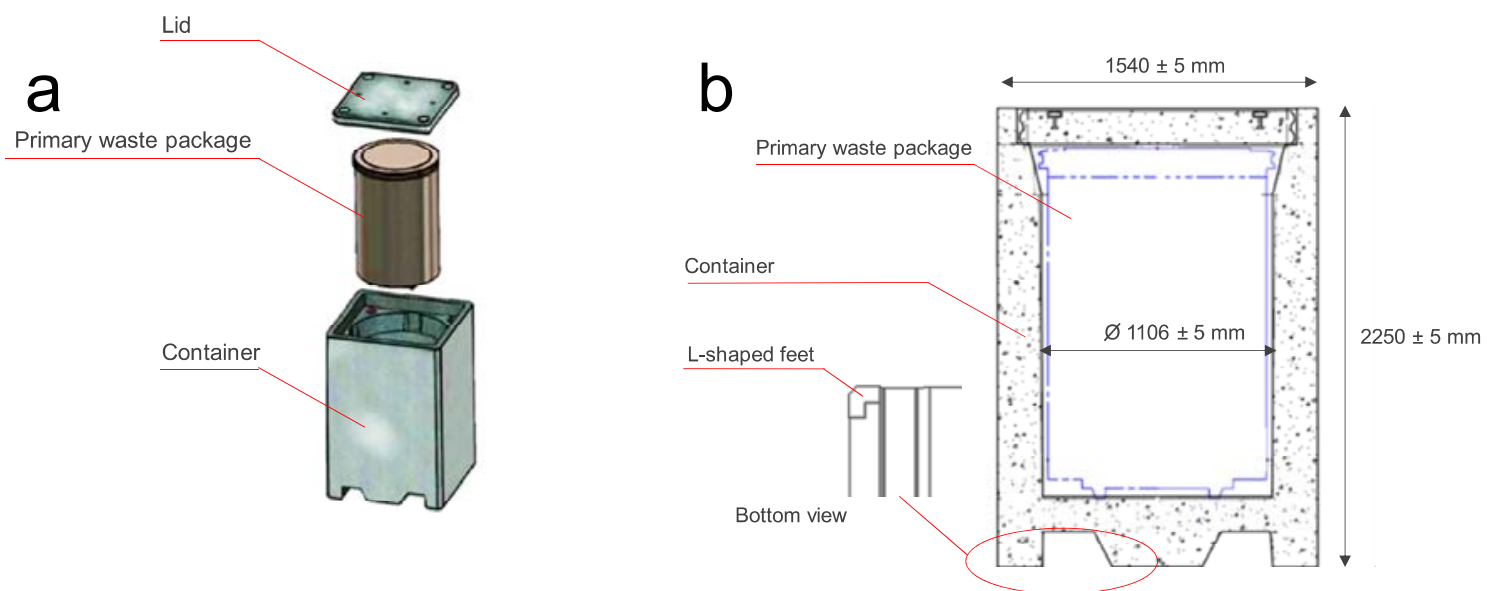

Figure 2. Description of the radioactive waste container prototype: a) schematic of the different parts of the radioactive waste package, and b) detailed dimensions of the concrete container. container prototype.

\begin{tabular}{|l|r|}
\hline Total steel reinforcement & $360 \mathrm{~kg}$ \\
\hline Lid & $662 \mathrm{~kg}$ \\
\hline Primary waste package & $3831 \mathrm{~kg}$ \\
\hline Reinforced concrete container (empty) & $8417 \mathrm{~kg}$ \\
\hline
\end{tabular}


Experimental modal analysis was conducted on a radioactive waste package prototype. It was tested under two different states. First, the concrete container was tested empty. At this state the four screws on the lid were incompletely threaded, and a thin foam was placed in between the two bodies. Second, the concrete container hosted a dummy (non-radioactive) primary waste package; at this state the four screws on the lid were completely threaded. The applied torque onto the screws was not ascertained at both states; yet, they were noticeably different. Figure 3 shows three photos that describe handling operations of the dummy primary waste package and the concrete lid in between modal tests. The package was placed on a metallic platform, which was conceived to distribute the load during mechanical tests. Typical mechanical tests conducted in this platform consist in piling up several containers, which reproduce the in-service conditions [12]. These tests are not discussed herein.
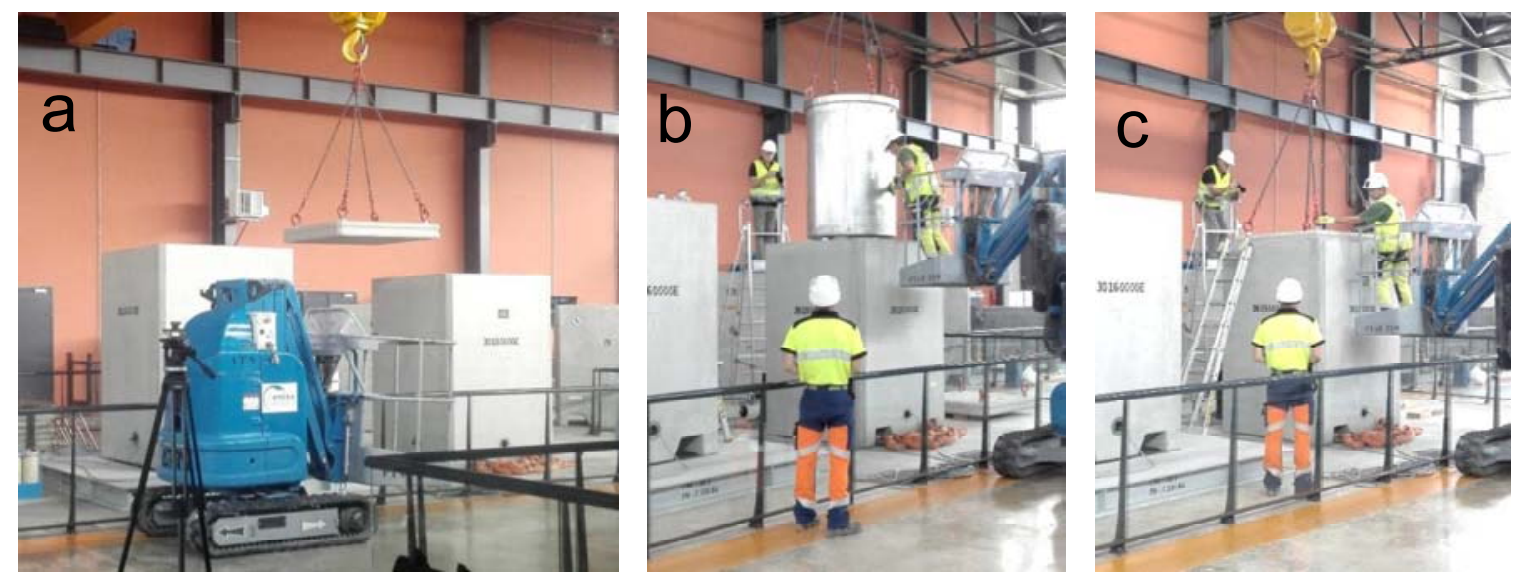

Figure 3. General overview and handling of the dummy primary waste package, a) remove the lid, b) loading the container with a dummy primary waste package, and c) closing of the waste package

Indicative values for elastic moduli and density of the precast concrete container were obtained on three cylindrical samples (length $\sim 0.225 \mathrm{~m}$ and diameter $\sim 0.115 \mathrm{~m}$ ), which were produced with identic concrete composition to the waste packages. To that end, the dynamic modulus and Poisson's ratio were ascertained according to the standard resonant frequency method ASTM C215-14 [36]. The dynamic modulus was derived from the longitudinal frequency mode, and Poisson's ratio was derived from the torsional mode of 
175 vibration, using the formulae provided in ASTM C215-14. The density of the concrete samples was measured from the mass at the moment of test and the actual dimensions of every sample, which were verified with a caliper. At the moment of test, the samples were fully matured (more than 1 year after casting). For reference, the 28-day compressive strength is $\sim 45 \mathrm{MPa}$. The Table 2 lists the physical properties of the concrete samples. These physical properties are used later on as guidance in the numerical simulations.

Table 2. Physical properties of the concrete samples. Mean values \pm standard deviation.

\begin{tabular}{|r|c|c|}
\hline Dynamic modulus, $\boldsymbol{E} \mathbf{( G P a )}$ & Poisson's ratio, $\boldsymbol{v}$ & Density $\left.\boldsymbol{\rho} \mathbf{( k g} / \mathbf{m}^{\mathbf{3}}\right)$ \\
\hline $39 \pm 1$ & $0.18 \pm 0.01$ & $2320 \pm 10$ \\
\hline
\end{tabular}

\section{$2.2 \quad$ Experimental modal analysis}

The ways to conduct experimental modal analysis (EMA) are manifold. In this study, a roving hammer test was conducted to identify resonant frequencies and modal shapes of the concrete container. The advantages of a roving hammer test against other alternatives are that it is relatively inexpensive, it can be set-up in very short time, and virtually, an unlimited number of degrees of freedom can be tested. The roving hammer test was conducted on a regular grid placed on a face of the container. It consisted of 80 degrees of freedom: 10 rows by 8 columns every $20 \mathrm{~cm}$. The vibration responses were obtained by striking the surface of the container with a modal hammer (Bruel \& Kjaer model 8207, $0.225 \mathrm{mV} / \mathrm{N}$ ). An accelerometer (Bruel \& Kjaer model 4525B, $1.046 \mathrm{mV} / \mathrm{m} \cdot \mathrm{s}^{-2}$ ) was glued on the surface which sensed the out-of-plane vibration. Figure 4 shows a schematic representation of the test configuration, and the relative positions of the grid with regard the accelerometer.

$$
H_{p}(\omega)=\frac{X_{p}(\omega)}{F_{p}(\omega)},
$$


where $F_{p}(\omega)$ is the Fourier transform of the force signal, and $X_{p}(\omega)$ is the Fourier transform of the acceleration signal. Since not all resonant frequencies have meaningful spectral amplitude at all measured degrees of freedom $p$, the squared singular values of the vector $\left[H_{1}\left(\omega_{i}\right), H_{2}\left(\omega_{i}\right), \ldots, H_{80}\left(\omega_{i}\right)\right]$, were computed at every frequency (or spectral line, $\omega_{i}$ ), to obtain a representative spectrum of the whole grid. This approach is termed complex mode indication function [37], [38]. The imaginary part of the accelerance (Eq. 1) is much more discriminating with respect to close modal frequencies [38]. Therefore, only the imaginary part of the accelerance was used to identify the resonant frequency peaks. Furthermore, the corresponding modal shapes were obtained by mapping the corresponding imaginary part of Eq. 1 onto the grid. Recall that the imaginary part of the accelerance is proportional to the modal displacement at a given resonant frequency peak [37], [39]. Only modes up to $\sim 1000 \mathrm{~Hz}$ were considered. This cutoff frequency was determined for a decrease of $90 \%$ of the input energy force.
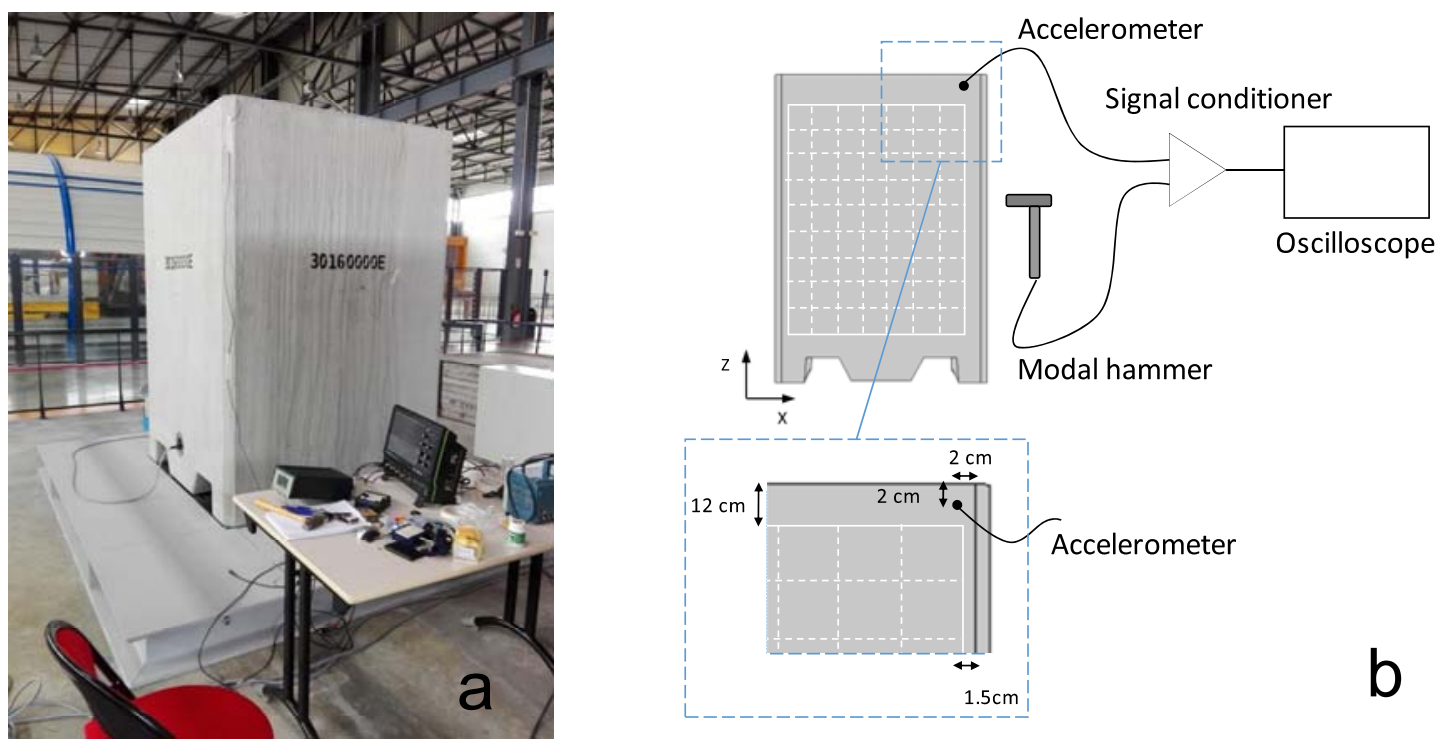

Figure 4. General overview of the container which lays on a metallic platform, and b) schematic representation of the test configuration showing the relative position of the measured degrees of freedom with regard the geometry of the container: a 10x8 grid every $20 \mathrm{~cm}$ placed on the front face (not to scale).

\section{Experimental modal analysis results}

The Figure 5 shows the eigenvalue spectra resulted from the singular value decomposition of the imaginary part of the accelerance obtained for the unloaded and 
215 loaded conditions. The spectra show different frequency peaks, which frequently appear 216 closely spaced. In both cases, a number of 20 resonant frequency peaks were identified, 217 ranging from 200 to $1000 \mathrm{~Hz}$. These are shown as vertical dashed lines in Figure 5. Low 218 frequency contributions $(<100 \mathrm{~Hz})$ were also identified, which correspond to rigid body 219 modes. However, their amplitudes are two orders of magnitude lower than those corresponding to resonant mode peaks (note logarithmic scale in Figure 5). Figure 6 shows the mode shapes corresponding to the 20 extracted resonant frequency peaks at the unloaded state. Similar mode shapes and in the same order were obtained after loading. However, after loading, all resonant frequency peaks shifted upward in different extents: between 0.1 and $4 \%$. The biggest difference was found for the lowest identified resonant frequency mode. This effect indicates that the load of the dummy primary waste package modified the dynamic properties of the structure. In the following, finite element modeling was used to interpret the observed behavior.

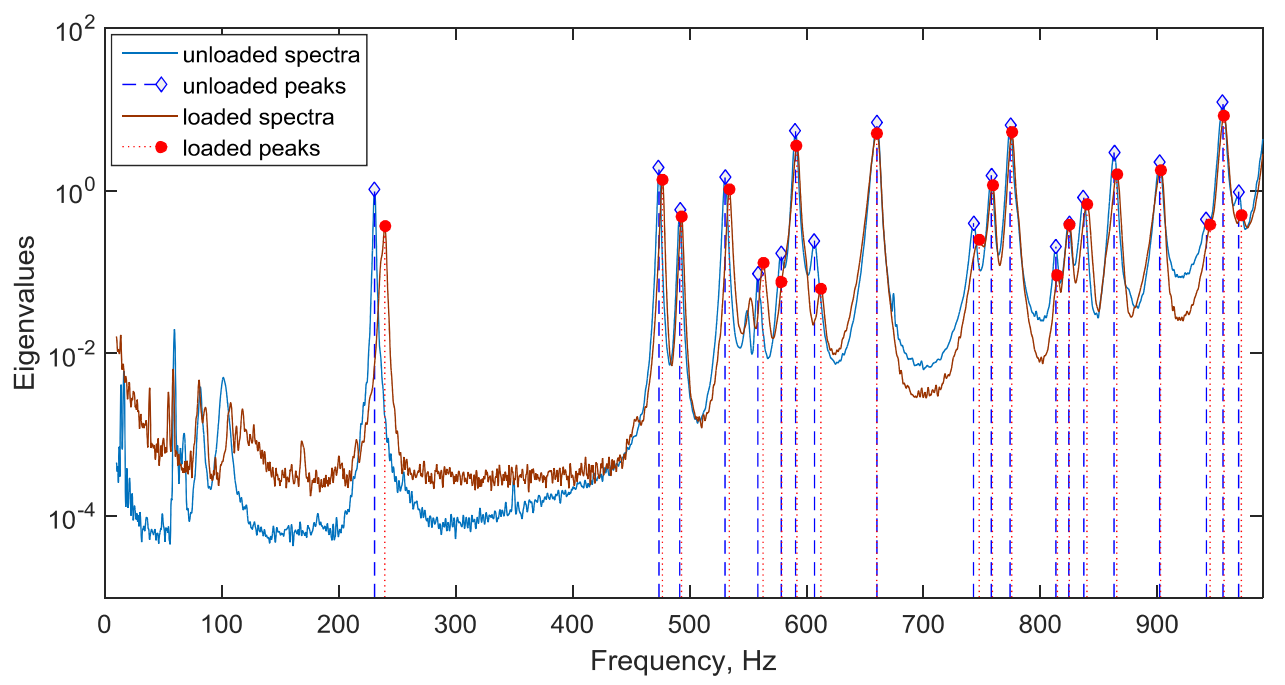

Figure 5. Resonant spectra obtained before and after loading the container with a dummy primary waste package. A number of 20 resonant frequency peaks were detected between $200 \mathrm{~Hz}$ and $1000 \mathrm{~Hz}$. 

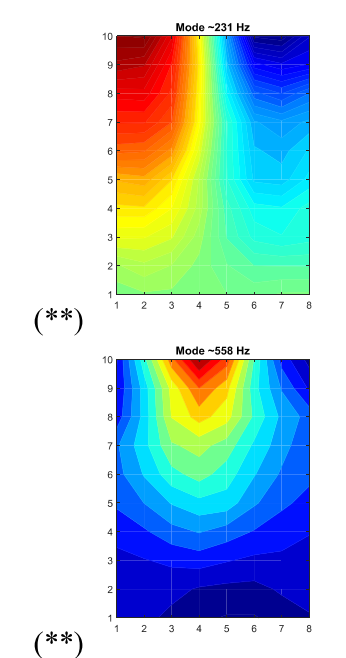

$(* *)$

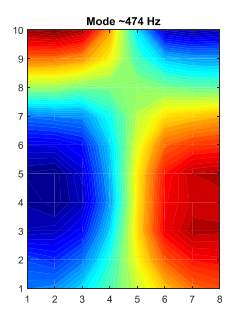

$(* *)$
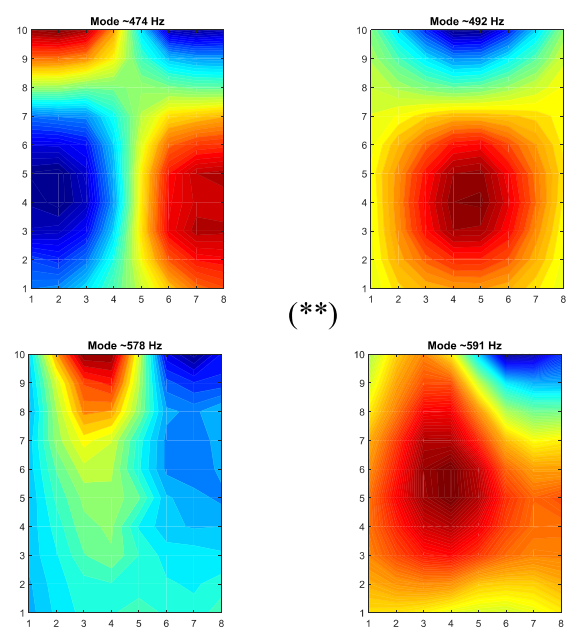

$(* *)$
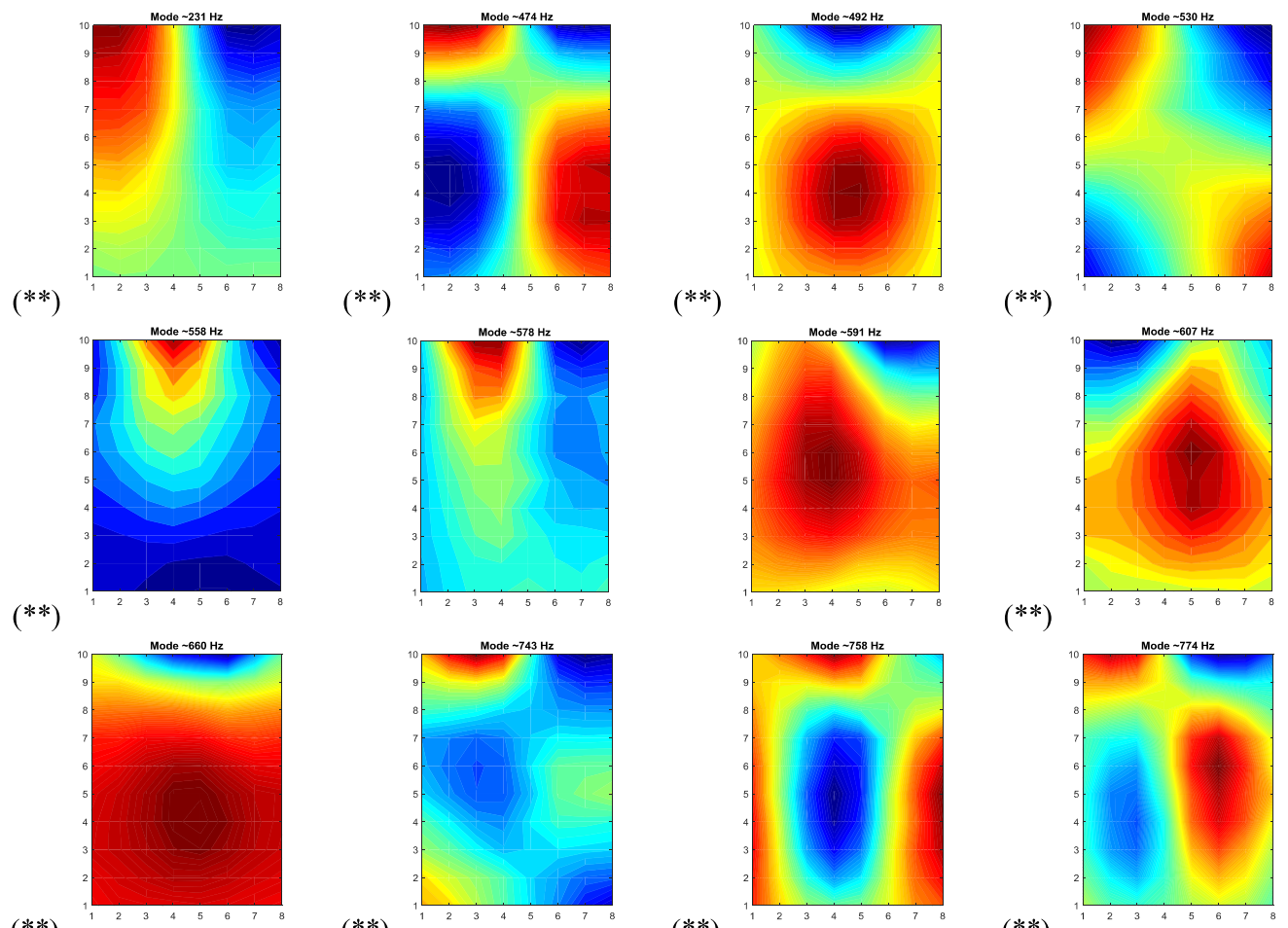

$(* *)$
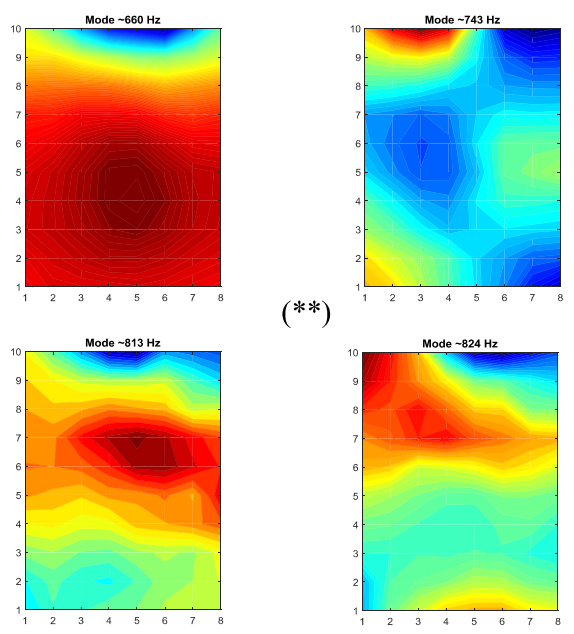

$(* *)$

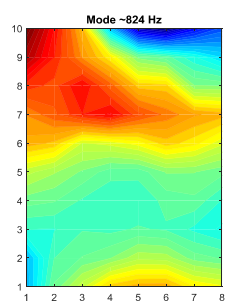

$(* *)$
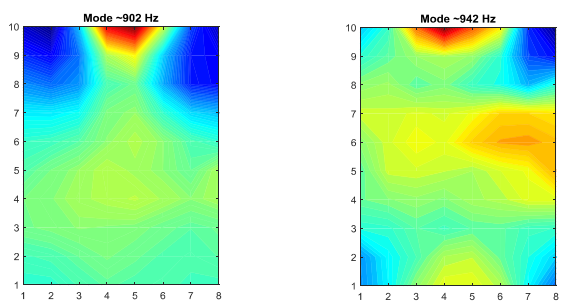

$(* *)$

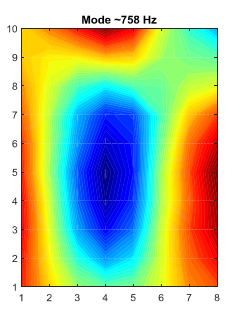

$(* *)$

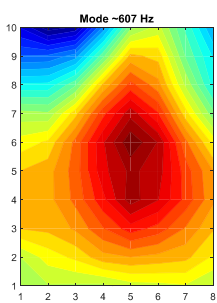

$(* *)$

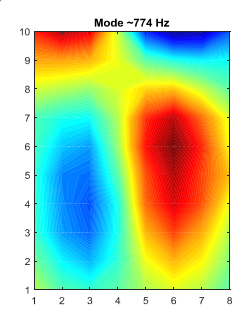

$(* *)$
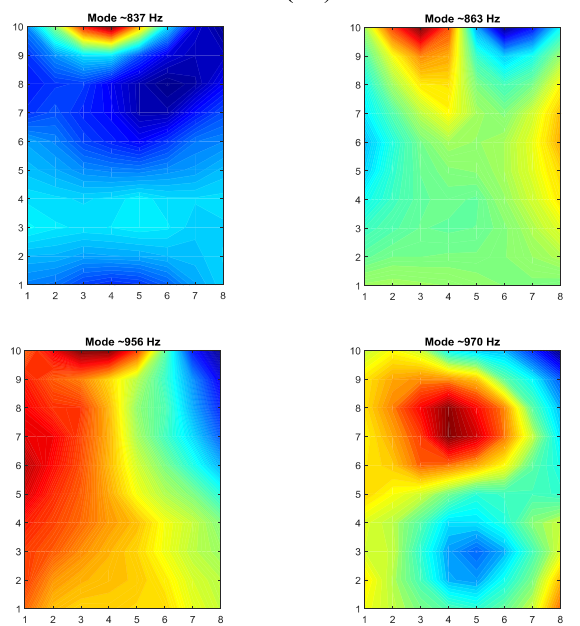

Figure 6. Experimental modal shapes (out-of-plane motion) obtained on the front face of the container. The symbols (**) denote that these mode shapes were paired and used for the FEM updating later on.

\section{$4 \quad$ Finite element modelling}

Figures $7 \mathrm{a}$ and $7 \mathrm{~b}$ show a schematic description of the boundary conditions of the

231 numerical model of the concrete container, for the unloaded (Figure 7a) and loaded states

232 (Figure 7b). Massless spring elements (denoted with subscript tel, which stands for thin elastic layer) were used to describe the boundary condition between the lid and the concrete 
container. These springs accommodate the different nodal displacements between the two bodies in $x, y$ and $z$ directions, with a preset spring constant $\left(K_{t e l}\right)$. These springs were considered to have similar stiffness values in every direction, thus $K_{t e l, x}=K_{t e l, y}=K_{t e l, z}$. Analogously, massless spring elements ( $K_{s p f}$, subscript $s p f$ stands for spring foundation) model the boundary condition between the floor and the four L-shaped feet of the container. Both, $K_{s p f}$ and $K_{t e l}$ elements were distributed on their respective contacting areas. Moreover, additional mass $\left(A_{\text {mass }}\right)$ was added to the bodies to consider the mass of the steel reinforcement, along with deviations from the measured concrete density $\left(\rho=2320 \mathrm{~kg} / \mathrm{m}^{3}\right)$. Therefore, the density of concrete was kept constant in the numerical simulations, and the parameter $A_{\text {mass }}$ was used as updating parameter. Linear elastic and isotropic behavior was considered. In the particular case of the loaded container (Figure $7 \mathrm{~b}$ ) the load corresponding to the weight of the primary waste package was distributed on the available surface $\left(\sim 1 \mathrm{~m}^{2}\right)$, and massless spring elements $\left(K_{s p f}^{l}\right)$ were used to constrain the movement at this zone. Again, these springs were considered to have similar stiffness values in $x, y$ and $z$ directions.

Different alternatives were considered to render an explanation of the relative increase of resonant frequencies with regard the unloaded state. On the one hand, dead loads on the container may lead to a local increase of stiffness because of geometric nonlinearity, and so, leading to an increase of resonant frequencies [40], [41]. On the other hand, nonlinear elastic behavior can further lead to stress dependent resonant frequency variations [42]. However, for given boundary conditions $\left(K_{t e l}=K_{s p f}=K_{s p f}^{l} 1 \mathrm{GN} / \mathrm{m} / \mathrm{m}^{2}\right)$, and considering third-order elastic constants for concrete - for instance, those obtained for concrete by Payan and coworkers [43] or by Lundqvist and Rydén [42]—, the sole effect of the dead load lead to very weak variations (less than $0.0001 \%$ ) of resonant frequencies with regard the same model without load. For reference, the effect of the load of the primary waste package $(\sim 3831 \mathrm{~kg})$ distributed on the available surface $\left(\sim 1 \mathrm{~m}^{2}\right.$, see Figure $\left.7 \mathrm{~b}\right)$ leads to a maximum Von Mises stress of roughly $\sim 0.7 \mathrm{MPa}$ in the volume of the container. Hence, the load of the primary waste package container is low enough to disregard nonlinear behavior. Conversely, the sole incorporation of the spring elements that constrain the loaded zone $\left(K_{s p f}^{l}\right)$ cause a meaningful increase of the resonant frequencies with regard the unloaded model (Figure 7a). In addition, the dead load may plausibly further constrain the 
boundary conditions on the four feet, and so, contributing also to increase the resonant frequencies. This latter option was considered henceforth.

A number of $N=45$ eigen-frequencies $\left(f_{n}\right)$ and their corresponding modal shapes $\left(\phi_{n}\right)$ were computed numerically for both models (Figures $7 \mathrm{a}$ and $7 \mathrm{~b}$ ). Figure $7 \mathrm{c}$ shows a set of representative mode shapes extracted out of the 45 computed modes. They were obtained for the unloaded state, and for the parameter values of $K_{t e l}=K_{s p f}=1 \mathrm{GN} / \mathrm{m} / \mathrm{m}^{2}, A_{\text {mass }}=360$ $\mathrm{kg}$, and the material properties listed in Table 2. A number of modal shapes correspond to the own resonant frequencies of the lid. For this particular set of model parameters, the modes 1 to 12,15 to $17,26,27$ and 45 correspond to the own resonant frequencies of the lid; an example of a resonant frequency of the lid is shown in the last picture in Figure $7 \mathrm{c}$. Experimental and numerical mode shapes were compared through the Modal Assurance Criterion $(M A C)$ as [44],

$M A C_{m, n}=\frac{\left|\phi_{n} \cdot \phi_{m}^{\prime}\right|^{2}}{\left|\phi_{n} \cdot \phi_{n}^{\prime}\right| \cdot\left|\phi_{m} \cdot \phi_{m}^{\prime}\right|}$,

wherein $\phi_{m}$ is the modal shape of the $m$ experimental mode, and $\phi_{n}$ is the numerical modal shape corresponding to the $n$ eigen-frequency. The $M A C$ is a measure of the similarity between the $m$ experimental modal shape, and the $n$ numerical modal shape. $M A C$ values vary between 0 and 1 . Figure 8 shows the pairwise comparison of the 20 extracted experimental modal shapes (those shown in Figure 6) with the 45 computed numerical modal shapes (those shown in Figure 7c). Herein, a pair was assigned for the maximum attained $M A C$ value, and if that was higher than 0.65. Moreover, those resonant modes corresponding to the lid were disregarded, since they produce negligible out-of-plane displacement on the measured surface. In some cases, the experimental modal shapes could be attributed to several numerical modal shapes. For instance, the $16^{\text {th }}$ experimental mode shape could be assigned to two different numerical modes (see Figure 8, and inset captions). This particular mode of vibration was not used to prevent from false assignation during the optimization process. As a result, a number of 13 modes could unequivocally be assigned, out of the 45 numerical modes (circle markers in Figure 8). These vibration modes were retained for the inversion of the parameters of the numerical model. 


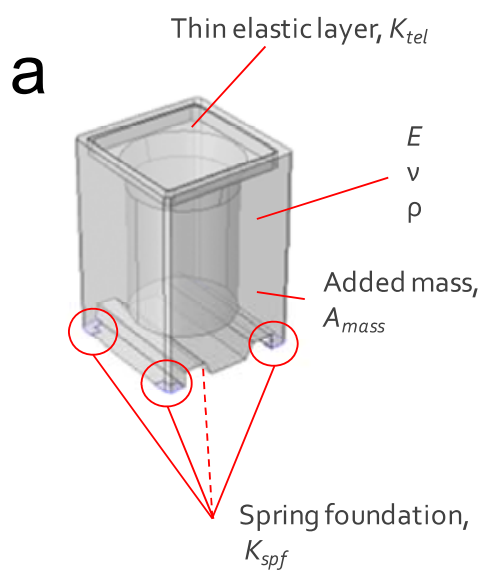

Updating parameters: $E, v, K_{\text {spf }}, K_{\text {tel }}, A_{\text {mass }}$

\section{C}

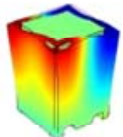

$13\left({ }^{* *}\right)$

$22(* *)$
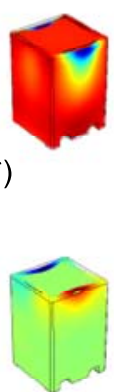

$\left.30{ }^{* *}\right)$

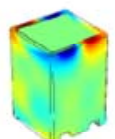

36

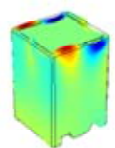

14
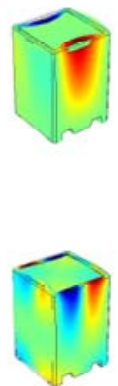

23

37

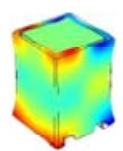

$\left.311^{* *}\right)$

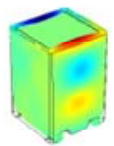

$18\left({ }^{* *}\right)$

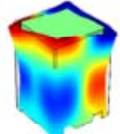

.

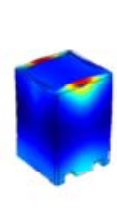

24

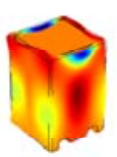

$32(* *)$

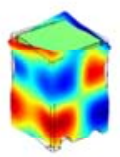

38

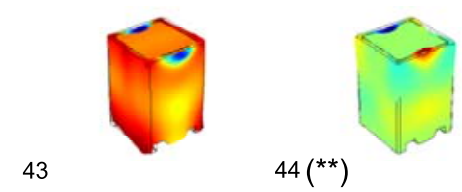

43

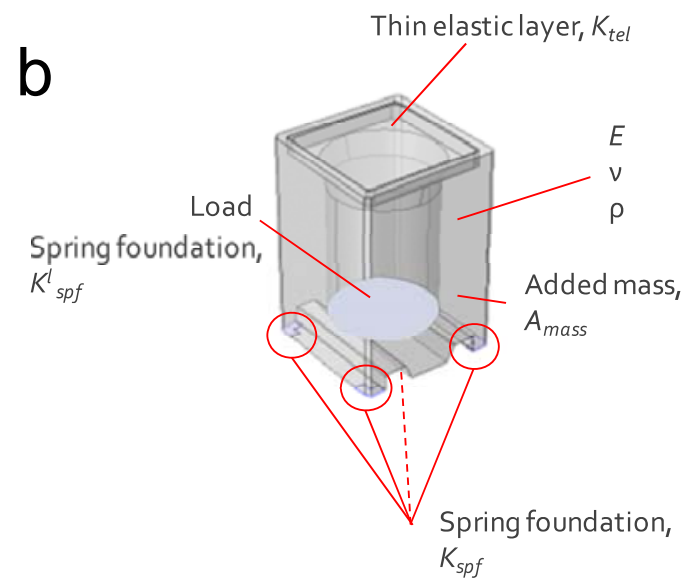

Updating parameters: $E_{1} v, K_{s p f}, K_{t e l}, A_{\text {mass }}, K_{s p f}^{l}$

42

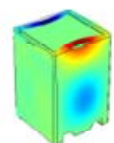

$19(* *)$

$20\left({ }^{* *}\right)$
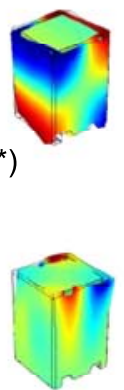

28

$29\left({ }^{* *}\right)$

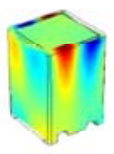

21

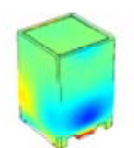

25

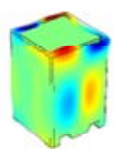

$33(* *)$

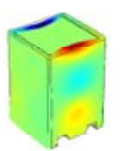

34

$35\left({ }^{* *}\right)$
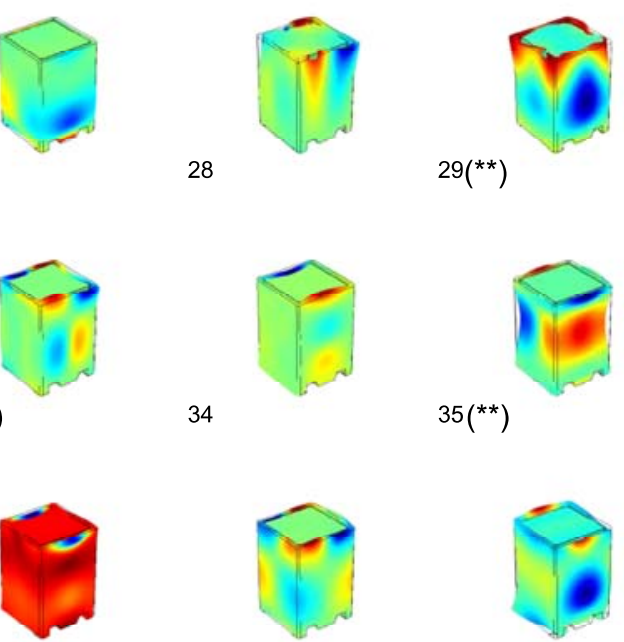

$39\left({ }^{* *}\right)$

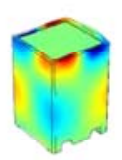

40

41

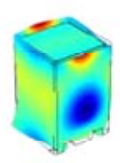

(*)

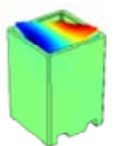

Figure 7. Description of the boundary conditions and the physical parameters of the numerical mode, a) unloaded, and b) loaded container. c) Representative modal shapes corresponding to the out-of-plane displacement of the front face of the unloaded container; (*) last picture (bottom right) shows a representative mode of vibration of the lid. The symbols (**) denote that these mode shapes were paired and used for the FEM updating. 


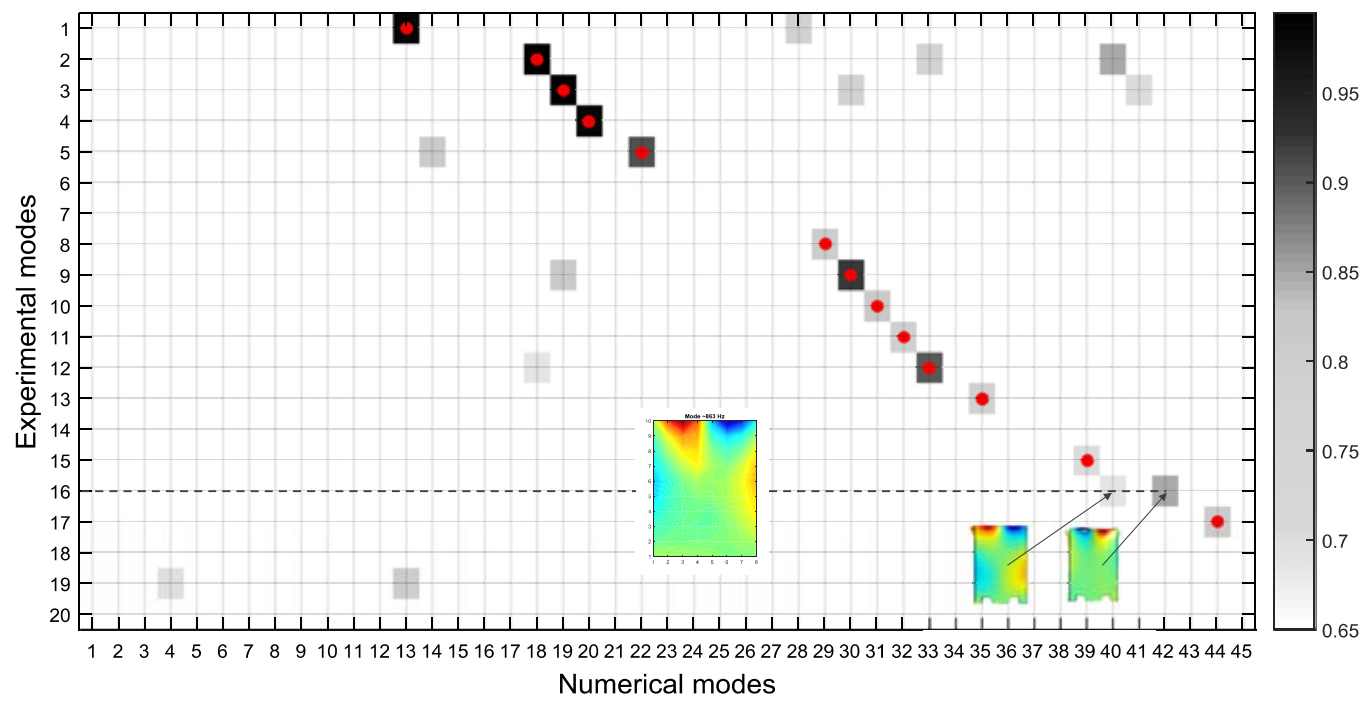

Figure 8. Modal Assurance Criterion values obtained for pairwise comparisons between numerical and experimental modal shapes. Circle markers represent paired modes, which were retained for the optimization problem.

\section{Optimization problem and sensitivity analysis}

Given that the actual material properties and boundary conditions are unknown, an optimization problem can be formulated. That is, to find the values of the set of unknown parameters of the numerical model $(\bar{p})$, that minimize the differences between experimental and numerical results. In case of the numerical model corresponding to the unloaded state, the set of the unknown parameters are: the modulus $(E)$, the Poisson's ratio $(v)$, the spring constant of the spring foundation $\left(K_{s p f}\right)$, the spring constant of the thin elastic layer $\left(K_{t e l}\right)$, and the added mass $\left(A_{\text {mass }}\right)$. Therefore, the optimization problem can be formulated as

304 subjected to upper and lower boundaries, $\bar{p}_{\text {lower }} \leq \bar{p} \leq \bar{p}_{\text {upper }}$, and where the cost function $305 f_{c}(\bar{p})$ can be written as the sum of weighted squared relative differences between experimental (subscript $m$ ) and numerical (subscript $n$ ) frequency values as 
$f_{c}(\bar{p})=1 / N \cdot \sum_{m=1}^{M} \sum_{n=1}^{N} w_{n, m} \cdot\left(\frac{f_{n}-f_{m}}{f_{m}}\right)^{2}$

$w_{n, m}$ is a weighting factor that equals 1 if the mode is paired, and 0 elsewhere. Note that not all selected experimental modes may be paired during the optimization process, hence the cost function in Eq. 4 represents an average error per mode. Other cost functions have been considered elsewhere wherein $M A C$ values also weight on the cost function; see for instance references [23] and [31].

As a first approximation to the optimization problem a full factorial three level $\left(3^{k}\right)$ design of experiments (DOE) was conducted; $k$ stands for the total number of factors, herein $k=5$ for the numerical model corresponding to the unloaded state (see Figure $7 \mathrm{a}$ ), and $k=6$ for the numerical model corresponding to the loaded state (see Figure $7 \mathrm{~b}$ ). The objectives of this initial analysis are i) to estimate the global sensitivity of the numerical model to model parameters variations, and ii) get an initial estimation of the parameter values that minimize the cost function (Eq. 4). This was achieved through the surface response methodology [45]. The surface response methodology consists in fitting an empirical model to the data generated by the application of a DOE, and find their critical values (in this case the minimum). The $3^{k}$ full factorial design allows estimation of a quadratic model as

$f_{c}^{\prime}(\bar{p})=a_{0}+\sum_{i=1}^{k} a_{i} X_{i}+\sum_{i=1}^{k} \sum_{j=1}^{k} a_{i j} X_{i} X_{j}+\sum_{i=1}^{k} a_{i i} X_{i i}^{2}+$ error,

wherein, $a_{0}, a_{i}, a_{j}, a_{i i}$ and $a_{i j}$ are the fitting coefficients of the quadratic model, and the set of parameters is $\bar{p}=\left[X_{1}, \ldots, X_{k}\right]$. Table 3 shows the factor levels for the set of parameters considered in the numerical models: 5 parameters for the unloaded state $\left(X_{1}\right.$ to $\left.X_{5}\right)$, and 6 parameters for the loaded state $\left(X_{1}\right.$ to $\left.X_{6}\right)$. The factor levels were chosen close to the indicative values obtained for the elastic modulus and Poisson's ratio of the concrete (those listed in Table 2). Conversely, since indicative values for boundary conditions $\left(K_{s p f}, K_{t e l}\right.$, and $K_{s p f}^{l}$ ) are not available, these were allowed to vary in a wider range. The numerical 
models were evaluated at the resulting 243 parameter combinations for the unloaded state, and at the 729 for the loaded state. Then, the resulted numerical eigen-frequencies and modal shapes were paired to the EMA data, and so the cost function (Eq. 4) was evaluated for every parameter combination. Once the empirical model in Eq. 5 is fitted to the cost function values obtained for all the $3^{k}$ combinations of parameters, a minimum point can be estimated. Such estimated minimum can be then used to narrow the space solution to be explored by a genetic algorithm (GA). From an initial population (say sets of parameters), genetic algorithms mimic "natural selection" to select sets of parameters that enhance the cost function. The members of the population are combined and selected as a function of how they perform on the cost function (or fitness value), to reproduce an enhanced generation. Crossover and mutation operators are applied through generations. The crossover function defines how members of the population create next generation, and the mutation function, introduces diversity in the population by introducing random changes on them. In general, the initial population can be generated randomly. However, the use of a priori knowledge may accelerate the convergence to a solution. Herein, the initial population was narrowed to $\pm 10 \%$ of the estimated minimum by the surface response method. Note, that the space solution is not strictly constrained within these boundaries, but they serve to provide an initial population which is randomly generated within these boundaries. There is a number of applications wherein the application of the surface response methodology has been successfully combined with genetic algorithms in optimization problems [46]. The population size was set to 25 in both cases. The crossover and mutation rates were set to 0.8 and 0.1 . The GA was stopped once a preset number of generations or a threshold value of the cost function is attained; herein, 25 generations or $10^{-4}$ respectively. Further refinement in the optimization problem can be achieved by using the obtained solution by the GA algorithm, as starting point in a nonlinear constrained minimization; herein, through the interior point algorithm. Examples of successful application of such hybrid genetic algorithms for FEM updating applications can be found in [23], [31], [34]. Figure 9 summarizes the optimization process conducted herein. 
Table 3. Factor levels used in the three level full factorial design.

\begin{tabular}{|l|l|r|r|r|}
\hline \multicolumn{2}{|l|}{ Parameter } & \multicolumn{1}{l|}{ Upper level } & \multicolumn{1}{l|}{ Intermediate level } & \multicolumn{2}{l|}{ lower level } \\
\hline $\mathrm{X}_{1}$ & Modulus $(\mathrm{GPa})$ & 40 & 35 & 30 \\
\hline $\mathrm{X}_{2}$ & Poisson's ratio & 0.300 & 0.225 & 0.150 \\
\hline $\mathrm{X}_{3}$ & $K_{\text {spf }}\left(\mathrm{GN} / \mathrm{m} / \mathrm{m}^{2}\right)$ & 10.00 & 5.05 & 0.10 \\
\hline $\mathrm{X}_{4}$ & $K_{\text {tel }}\left(\mathrm{GN} / \mathrm{m} / \mathrm{m}^{2}\right)$ & 10.00 & 5.05 & 0.10 \\
\hline $\mathrm{X}_{5}$ & $A_{\text {mass }}(\mathrm{Kg})$ & 1000 & 500 & 0 \\
\hline $\mathrm{X}_{6}$ & $K_{\text {spf }}\left(\mathrm{GN} / \mathrm{m} / \mathrm{m}^{2}\right)$ & 10.00 & 5.05 & 0.10 \\
\hline
\end{tabular}

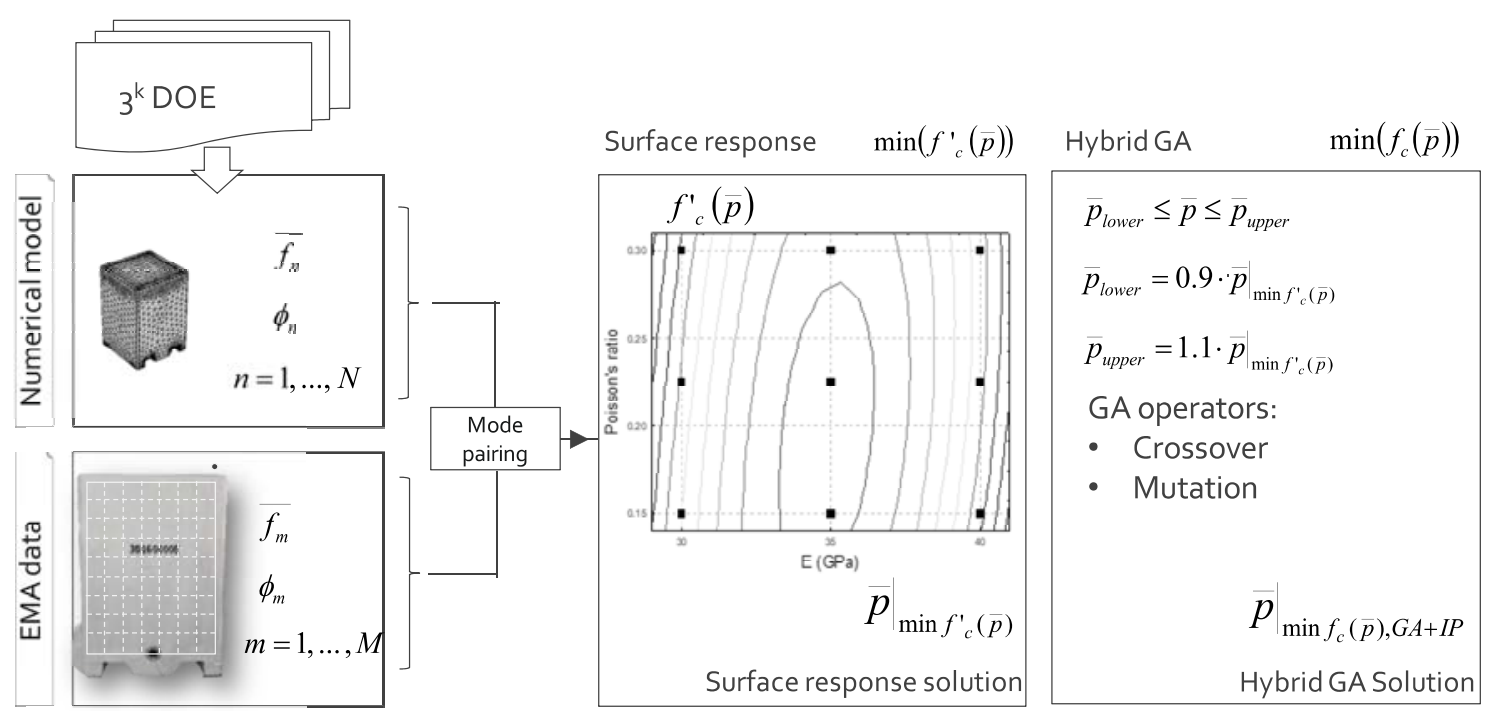

Figure 9. Flowchart representing the data analysis conducted for FEM updating in this study.

One of the interests of performing a $3^{k} \mathrm{DOE}$ is to analyze the global sensitivity of the FEM to the model parameter variations. For the sake of conciseness, only the main effects are shown. Figures 10a to $10 \mathrm{f}$ show the main effects for the cost function. From results it is drawn that the cost function is sensible to the variations of $E, K_{\text {tel }}$, and $A_{\text {mass }}$, within the levels of the DOE. It was the less for all the cases where $E$ was set to $35 \mathrm{GPa}$ (Figure 10a). In addition, the cost function increases monotonically when $K_{t e l}$ increases (Figure 10d), and decreased with increasing $A_{\text {mass }}$ (Figure 10e). Conversely, the cost function showed less variability with the variations of Poisson's ratio (Figure 10b), $K_{s p f}$ (Figure 10c), and $K_{s p f}^{l}$ (Figure 10f). Yet, the regression analysis showed that all the linear terms were statistically significant in both cases, including a number of quadratic and the interaction terms in the Eq. 5 (we deemed statistical significance for p-values $<0.05$; the 
regression results are not shown herein). The explained variance was $98 \%$ for the unloaded case, and $85 \%$ for the loaded one. Subsequently, the fitted equations were used to obtain the set of parameters that minimize $f^{\prime}{ }_{c}$, and initialize the GA.
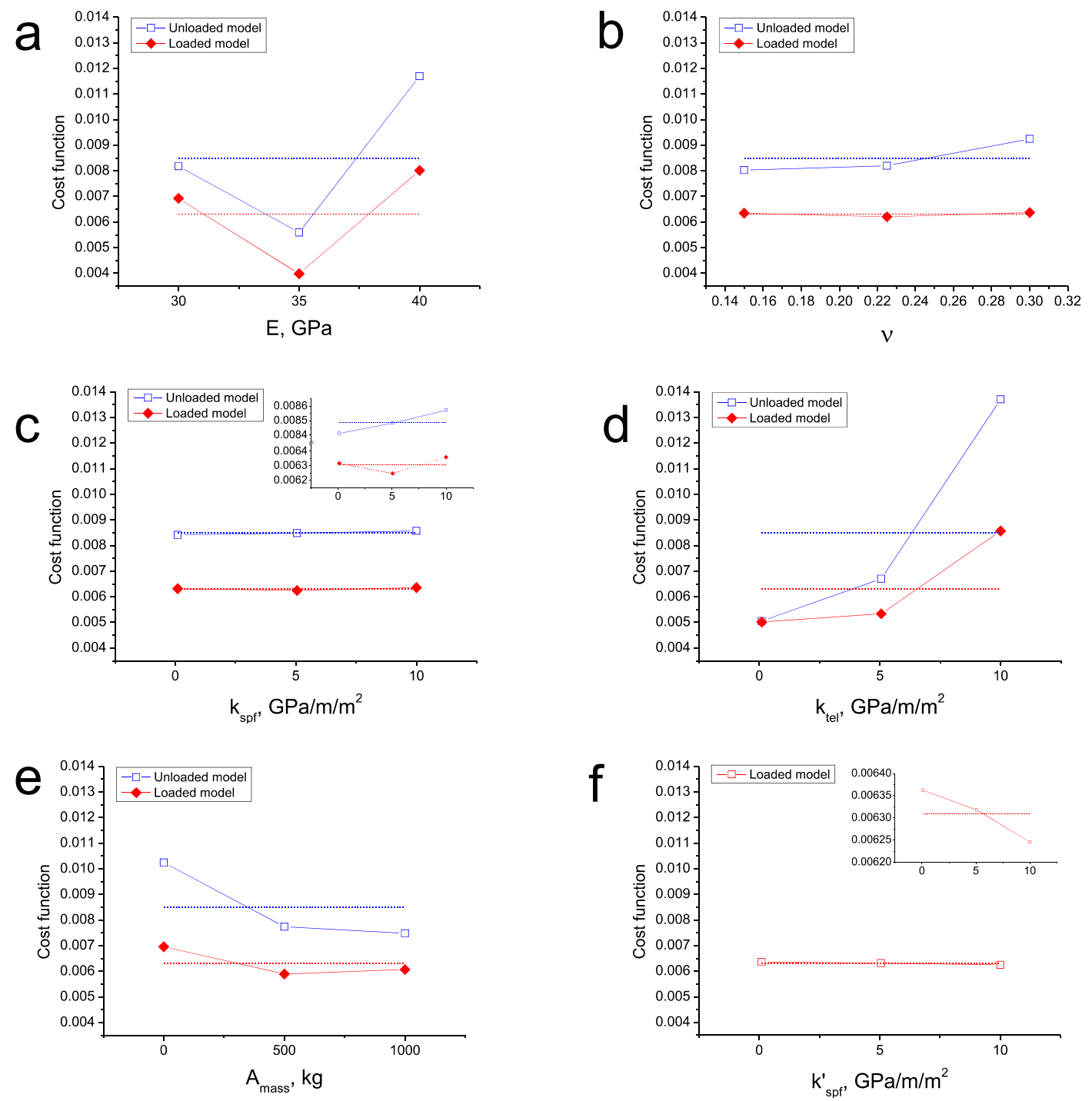

Figure 10. Main effects plots (data means) for cost function values investigated at the $3^{k} D O E$ points, for loaded and unloaded FEM. a) Elastic modulus, b) Poisson's ratio, c) $K_{s p p}$ d) $K_{\text {teb }}$ e) $A_{\text {mass }}$, and f) $K_{s p f}^{l}$. Dashed lines represent the global mean.

Table 4 summarizes the results of the FEM updating for unloaded and loaded states. For reference, intermediate solutions across the different steps of the optimization process are also listed: the best $3^{k}$ DOE point, and the surface response minimum. The elastic properties $(E$ and $v)$ were found to be in good agreement with those found for cylindrical 
samples (Table 2). From results, it is found that the loaded containers may be well represented by increasing the stiffness of the spring foundation elements. Moreover, Table 5 compares the EMA data and the FEM results obtained during the different steps, and for both investigated states. $M A C$ values remained almost constant across the optimization steps, while the resonant frequency values varied in larger extent. The symbol (--) denotes modes that were not paired; thus $M A C<0.65$ at this optimization step. Finally, Figure 11a and $11 \mathrm{~b}$ show the predicted values as a function of the observed values and the resulted residuals for both states. Noticeably, the first four resonance modes are predicted with a relative error below 1\%. However, at higher frequencies, the relative error increases, roughly to $2 \%$. The relative misfits in FEM updating are in general attributed to the model assumptions: i) model structure errors, ii) model order errors (nonlinear behavior); iii) model parameter errors, and iv) errors in experimental data [20]. Notwithstanding, the resulting numerical models describe fairly well the dynamic mechanical behavior of the packages. These results are expected to be used as a reference condition for future experimental campaigns. Finally, a local sensitivity analysis was conducted through a oneat-a-time approach. It consists in investigate the effect of every parameter individually to a higher and a lower value, while keeping other parameters at the reference value. Herein, we investigated the local sensitivity within a $\pm 10 \%$ parameter variations. Figures $11 \mathrm{c}$ and $11 \mathrm{~d}$ show the local sensitivity analysis results for unloaded and loaded states. From, these results it is drawn that the cost function is dominated by the elastic modulus variations in both cases, while Poisson's ratio, the added mass, and the boundary conditions variations lead to minor variations of the result.

Table 4. Results of the set of the parameters of the numerical mode for both investigated states.

\begin{tabular}{|c|c|c|c|c|c|c|c|c|}
\hline & $\begin{array}{c}\mathbf{E} \\
(\mathbf{G P a})\end{array}$ & $\mathbf{v}$ & $\begin{array}{c}K_{\text {spf }} \\
(\mathbf{G N} / \\
\left.\mathbf{m} / \mathbf{m}^{2}\right)\end{array}$ & $\begin{array}{c}\boldsymbol{K}_{\text {tel }} \\
(\mathbf{G N} / \\
\left.\mathbf{m} / \mathbf{m}^{2}\right)\end{array}$ & $\begin{array}{c}A_{\text {mass }} \\
(\mathbf{k g})\end{array}$ & $\begin{array}{c}K_{s p f}^{l} \\
(\mathbf{G N} / \\
\left.\mathbf{m} / \mathbf{m}^{2}\right)\end{array}$ & $\begin{array}{c}f_{c}^{\prime} \\
\left(\cdot 10^{-4}\right)\end{array}$ & $\begin{array}{c}f_{c} \\
\left(\cdot 10^{-4}\right)\end{array}$ \\
\hline \multicolumn{9}{|l|}{ Unloaded (Figure 7a) } \\
\hline Best $3^{\mathrm{k}}$ DOE point & 35.00 & 0.15 & 5.05 & 0.10 & 500.0 & -- & -- & 3.16 \\
\hline Surface response minimum & 38.74 & 0.18 & 0.10 & 0.45 & 967.0 & -- & 1.82 & 2.04 \\
\hline Hybrid GA optimization & 35.85 & 0.17 & 5.26 & 0.77 & 576.8 & -- & & 1.77 \\
\hline \multicolumn{9}{|l|}{ Loaded (Figure 7b) } \\
\hline Best $3^{k}$ DOE point & 35.00 & 0.30 & 10.00 & 0.10 & 0 & 5.005 & -- & 5.89 \\
\hline Surface response minimum & 38.24 & 0.29 & 10.00 & 1.27 & 1000 & 10.00 & 12.63 & 3.57 \\
\hline Hybrid GA optimization & 35.59 & 0.19 & 7.72 & 1.23 & 524.7 & 6.58 & -- & 1.98 \\
\hline
\end{tabular}


Table 5. Comparison of EMA data and FEM results across the different optimization steps.

\begin{tabular}{|c|c|c|c|c|c|c|c|c|}
\hline & \multirow[t]{2}{*}{ Mode } & \multirow{2}{*}{$\begin{array}{l}\text { EMA } \\
\text { Freq. } \\
\text { (Hz) }\end{array}$} & \multicolumn{2}{|c|}{ Best $3^{k}$ DOE point } & \multicolumn{2}{|c|}{$\begin{array}{l}\text { Surface response } \\
\text { minimum }\end{array}$} & \multicolumn{2}{|c|}{$\begin{array}{l}\text { Hybrid GA } \\
\text { optimization }\end{array}$} \\
\hline & & & $\begin{array}{l}\text { Freq. } \\
(\mathrm{Hz})\end{array}$ & $M A C$ & $\begin{array}{l}\text { Freq. } \\
(\mathrm{Hz})\end{array}$ & $M A C$ & $\begin{array}{l}\text { Freq. } \\
(\mathrm{Hz})\end{array}$ & $M A C$ \\
\hline \multirow[t]{13}{*}{ Unloaded } & 1 & 230.7 & 220.9 & 0.98 & 228.4 & 0.98 & 231.1 & 0.98 \\
\hline & 2 & 474.0 & 470.9 & 0.99 & 479.5 & 0.99 & 475.3 & 0.99 \\
\hline & 3 & 491.7 & 486.0 & 0.99 & 493.9 & 0.99 & 489.7 & 0.99 \\
\hline & 4 & 530.3 & 521.4 & 0.98 & 518.7 & 0.98 & 523.1 & 0.98 \\
\hline & 5 & 558.3 & 540.9 & 0.89 & 548.2 & 0.90 & 544.6 & 0.90 \\
\hline & 6 & 606.9 & 605.8 & 0.82 & 616.5 & 0.80 & 612.1 & 0.81 \\
\hline & 7 & 660.2 & 659.4 & 0.92 & 675.2 & 0.92 & 667.9 & 0.92 \\
\hline & 8 & 742.8 & 749.2 & 0.81 & 740.4 & 0.82 & 751.6 & 0.82 \\
\hline & 9 & 758.0 & 757.6 & 0.81 & 769.6 & 0.79 & 763.3 & 0.80 \\
\hline & 10 & 774.0 & 761.3 & 0.90 & 775.8 & 0.90 & 767.1 & 0.90 \\
\hline & 11 & 813.1 & 802.5 & 0.76 & 818.5 & 0.77 & 807.8 & 0.75 \\
\hline & 12 & 837.1 & 842.0 & 0.74 & 852.2 & 0.70 & 846.3 & 0.74 \\
\hline & 13 & 901.9 & -- & - & - & -- & 928.2 & 0.83 \\
\hline \multirow[t]{13}{*}{ Loaded } & 1 & 239.5 & 232.3 & 0.99 & 241.03 & 0.99 & 237.7 & 0.99 \\
\hline & 2 & 476.8 & 485.0 & 0.99 & 480.16 & 0.99 & 479.4 & 0.99 \\
\hline & 3 & 493.2 & 490.8 & 0.99 & 486.20 & 0.99 & 491.4 & 0.99 \\
\hline & 4 & 534.0 & 524.3 & 0.98 & 524.19 & 0.98 & 534.3 & 0.98 \\
\hline & 5 & 562.8 & 553.0 & 0.75 & 550.09 & 0.75 & 553.6 & 0.75 \\
\hline & 6 & 612.3 & 622.5 & 0.73 & 620.08 & 0.82 & 617.2 & 0.74 \\
\hline & 7 & 660.0 & 686.1 & 0.95 & 675.48 & 0.94 & 670.6 & 0.94 \\
\hline & 8 & 747.7 & 764.8 & 0.67 & 752.84 & 0.67 & 760.9 & 0.65 \\
\hline & 9 & 759.1 & 786.7 & 0.81 & 772.25 & 0.81 & 766.1 & 0.80 \\
\hline & 10 & 775.5 & 790.0 & 0.89 & 775.50 & 0.88 & 769.4 & 0.88 \\
\hline & 11 & 824.7 & -- & -- & -- & -- & -- & -- \\
\hline & 12 & 839.7 & -- & -- & 839.83 & 0.83 & 848.6 & 0.70 \\
\hline & 13 & 902.8 & -- & -- & 944.00 & 0.89 & 9330 & 0.85 \\
\hline
\end{tabular}

406

407

408 

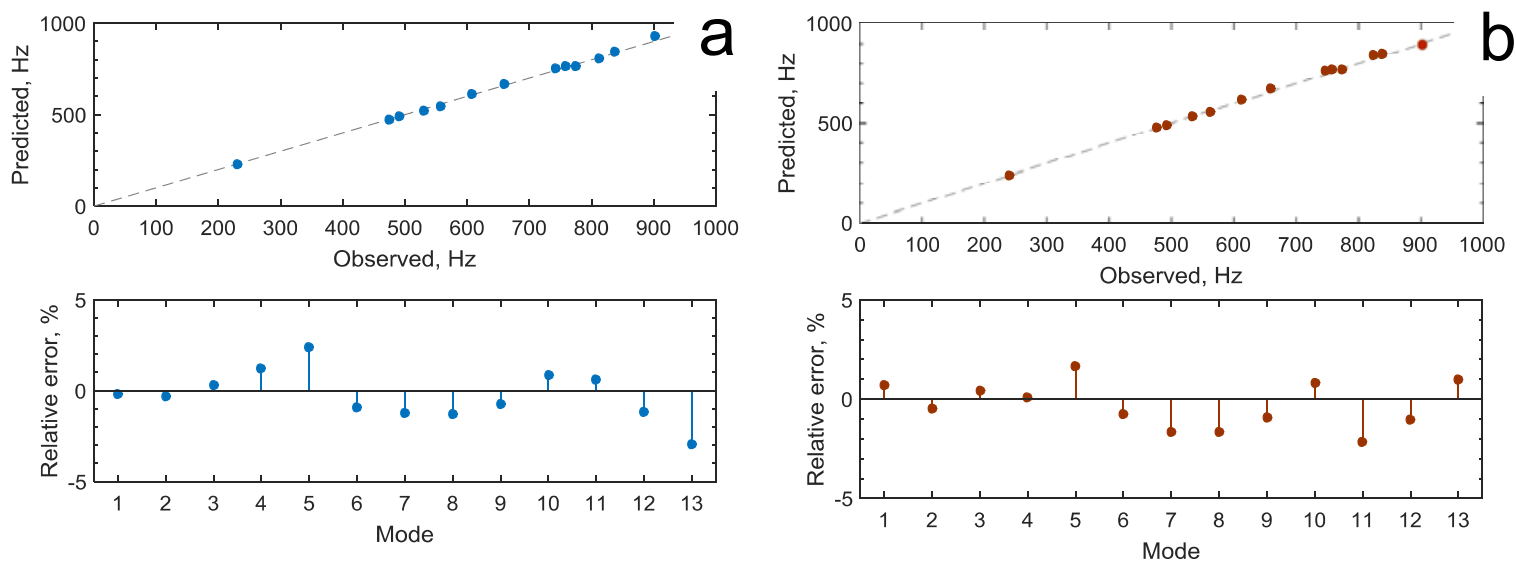

C
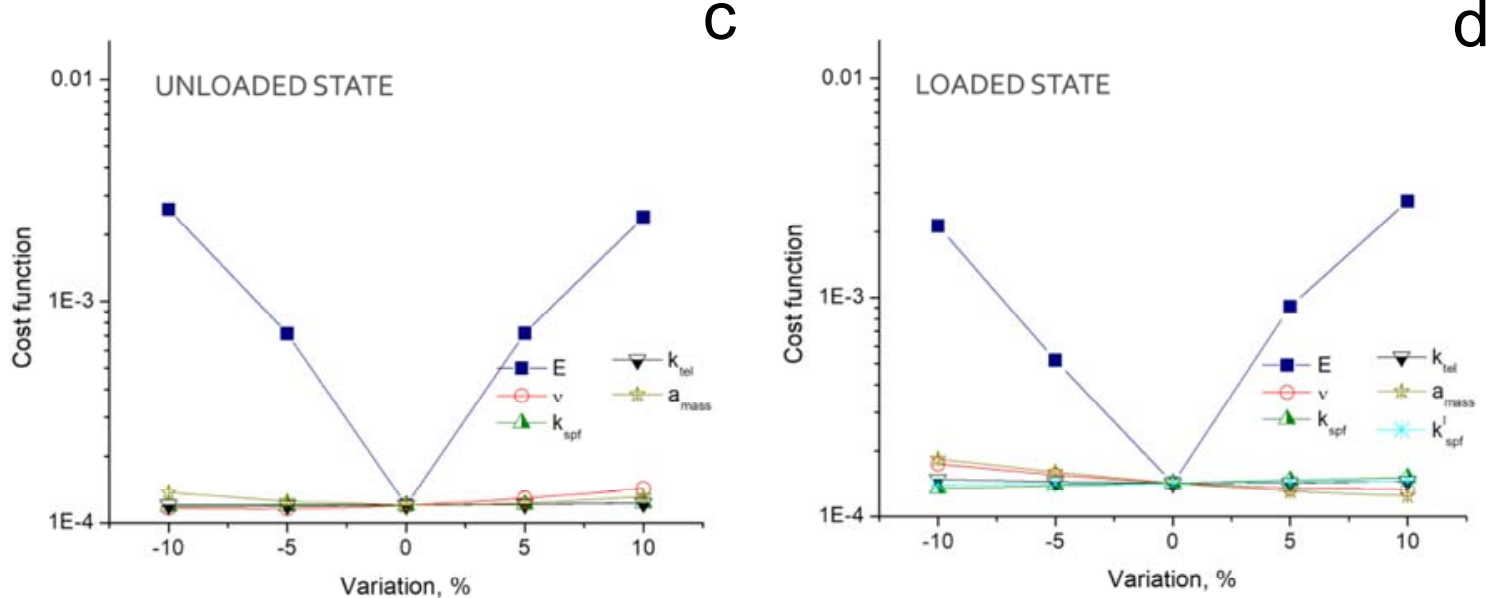

Figure 11. Comparison between experimental and numerical frequencies after the optimization for a) unloaded case, and b) loaded case, and sensitivity analysis, and one-at-a-time analysis for $\pm 10 \%$ variations for c) unloaded, and d) loaded states.

\section{Conclusions and prospects}

Experimental modal analysis has been applied on a prototype radioactive waste package. The prototype was tested under two different scenarios: the concrete container

414 was tested empty, and then, hosting a dummy primary waste package. Similar modal shapes

415 were identified in both cases. However, after loading the concrete container, all resonant

416 frequency modes consistently shifted upwards: between $4 \%$ and $0.1 \%$. EMA data (resonant 
frequencies and modal shapes) were used to benchmark finite element models that describe

418 the dynamic mechanical behavior of the concrete containers at both states. The latter was achieved through the formulation of an optimization problem that consists in finding the parameters of the numerical model that minimize the differences with regard the EMA data.

421 Herein, we first used a full factorial DOE which allowed investigation of the global model sensitivity to the input parameters. Such an analysis allows screening the parameters that dominate the dynamic properties within a range of values, get insight of the model quality, and get an initial estimation of the set of the numerical model parameters that minimize the differences with respect the EMA data. The optimization problem was subsequently solved through a genetic algorithm, within a set of parameter boundaries ensuing the analysis of the DOE. Such a methodology presented in this study was able to successfully calibrate finite element models that describe the mechanical behavior of the radioactive waste packages. Numerical models can be then used to predict the mechanical behavior of the radioactive waste prototypes, which may save considerable labor and budget in cumbersome experiments, and serve as baseline condition for the implementation of a modal-based SHM. Model updating can be used also to detect, locate and quantify damage severity [27], [34]. With regard this latter purpose, the following issues are subject of ongoing research:

(i) In the framework of the Cigéo project, it is foreseen that the containers be stacked (see Figure 1b). Thus, three different situations must be considered depending on the position of the container, each of them, being subjected to different boundary conditions. A similar FEM updating procedure can be conducted to obtain numerical models of the concrete containers at their final disposition in the radioactive waste repository.

(ii) The radioactive waste repository is expected to work at temperatures up to $\sim 65^{\circ} \mathrm{C}$, depending on the waste type. Previous researches [7], [47] have demonstrated that at and above such temperatures drying shrinkage in concrete leads to a decrease of the elastic properties. Furthermore, the elastic properties of concrete (as other ceramic materials) soften with increasing temperature [48], [49]. Therefore, eventual temperature 
fluctuations in the radioactive waste repository along with concrete aging are expected to cause variations on dynamic properties, and yet not being indicative of structural damage; or in a reverse sense, obscuring the presence of damage [16], [50]. These contentions oblige consideration of additional sensors that monitor operational conditions, and aid to remove the trends on the modal data driven by such. The interaction of these effects deserves further study.

(iii) In most practical cases, modal-based SHM leverages ambient vibrations (say wind loads, traffic, or seismic events) to obtain the dynamic characteristics of structures. Ambient vibrations do not seem feasible in the case of a geological radioactive waste repository. Therefore, practical implementation of a modal-based SHM appeals to the need of forced excitation systems, either shock or harmonic excitation. See for instance references [21], [51], [52], wherein different excitation devices have been successfully applied to determine the dynamic characteristics of buildings. These forced excitation alternatives can be built up in a robot, or permanently installed in the repository, for promoting the excitation of resonant frequencies periodically.

(iv) Finally, practical implementation of a modal-based SHM system must consider a cost-effective disposition of sensors regarding number, power consumption, maintenance and that in turn, maximize the probability of damage detection [53].

\section{Acknowledgements}

This work was performed with the support of the French government's programme: Investissements d'avenir, and operated by the French National Radioactive Waste Management Agency (Andra), project: Dynamique et contrôle nondestructif (DCND). The authors also thank the assistance of Sylvie Lesoille and Sandrine Bethmont from Andra on the experimental campaign. 


\section{Bibliography}

[1] S. Farin, T. Labalette, G. Ouzounian, F. Plas. Progress Towards Geological Disposal of High-Level and Intermediate-Level Long Lived Radioactive Waste at an Industrial Scale: The Cigéo Project in France, In: International Approaches for Nuclear Waste Disposal in Geological Formations: Geological Challenges in Radioactive Waste Isolation. Fifth Worldwide Review. B. Faybishenko, J. Birkholzer, D. Sassani, and P. Swift (Editors). Lawrence Berkeley National Laboratory, Sandia National Laboratories, LBNL-1006984, 2016.

[2] J. Kotatkova, J. Zatloukal, P. Reiterman, and K. Kolar, "Concrete and cement composites used for radioactive waste deposition," J. Environ. Radioact., vol. 178179, pp. 147-155, 2017.

[3] K. E. Kurtis, Y. Xi, M. A. Glinicki, J. Provis, E. R. Giannini, and T. Fu, "Can We Design Concrete to Survive Nuclear Environments?," Concr. Int., no. November, pp. 53-59, 2017.

[4] B. Pomaro, "A Review on Radiation Damage in Concrete for Nuclear Facilities: From Experiments to Modeling,” Model. Simul. Eng., vol. 2016, pp. 1-10, 2016.

[5] C. Andrade, I. Martínez, M. Castellote, and P. Zuloaga, "Some principles of service life calculation of reinforcements and in situ corrosion monitoring by sensors in the radioactive waste containers of El Cabril disposal (Spain)," J. Nucl. Mater., vol. 358, no. 2-3, pp. 82-95, 2006.

[6] G. S. Duffó, E. A. Arva, F. M. Schulz, and D. R. Vazquez, "Durability of a reinforced concrete designed for the construction of an intermediate-level radioactive waste disposal facility," J. Nucl. Mater., vol. 420, no. 1-3, pp. 382-387, 2012.

[7] I. Maruyama, H. Sasano, Y. Nishioka, and G. Igarashi, "Strength and Young's modulus change in concrete due to long-term drying and heating up to $90^{\circ} \mathrm{C}$," $\mathrm{Cem}$. Concr. Res., vol. 66, pp. 48-63, Dec. 2014.

[8] N. Trivedi and R. K. Singh, "Assessment of in-situ concrete creep: Cylindrical 
specimen and prototype nuclear containment structure," Constr. Build. Mater., vol. 71, pp. 16-25, Nov. 2014.

[9] S. Iliopoulos, D. G. Aggelis, L. Pyl, J. Vantomme, P. Van Marcke, E. Coppens, and L. Areias, "Detection and evaluation of cracks in the concrete buffer of the Belgian Nuclear Waste container using combined NDT techniques," Constr. Build. Mater., vol. 78, pp. 369-378, 2015.

[10] A. G. Davis, J. G. Evans, and B. H. Hertlein, "Nondestructive Evaluation of Concrete Radioactive Waste Tanks," J. Perform. Constr. Facil., vol. 11, no. November, pp. 161-167, 1997.

[11] J. M. Henault, G. Moreau, S. Blairon, J. Salin, J. R. Courivaud, F. Taillade, E. Merliot, J. P. Dubois, J. Bertrand, S. Buschaert, S. Mayer, and S. Delepine-Lesoille, "Truly distributed optical fiber sensors for structural health monitoring: From the telecommunication optical fiber drawling tower to water leakage detection in dikes and concrete structure strain monitoring," Adv. Civ. Eng., vol. 2010, 2010.

[12] G. Hermand, S. Bethmont, M. Landolt, and S. Lesoille, "Optical fiber for 3D imaging of deformations in concrete containers stacked," in Structural Health Monitoring 2017, 2017.

[13] G. Hearn and R. Testa, "Modal Analysis for Damage Detection in Structures," $J$. Struct. Eng., vol. 117, no. 10, pp. 3042-3063, 1991.

[14] A. Rytter, "Vibration based inspection of civil engineering structures," Ph.D. Dissertation, Department of Building Technology and Structural Engineering, Aalborg University, Denmark, 1993.

[15] S. Doebling, C. Farrar, and M. Prime, "A summary review of vibration-based damage identification methods," Shock Vib. Dig., vol. 30, no. 2, pp. 91-105, 1998.

[16] W. Fan and P. Qiao, "Vibration-based Damage Identification Methods: A Review and Comparative Study," Struct. Heal. Monit. An Int. J., vol. 10, no. 1, pp. 83-111, 
[17] S. Das, P. Saha, and S. K. Patro, "Vibration-based damage detection techniques used for health monitoring of structures: a review," J. Civ. Struct. Heal. Monit., vol. 6, no.

[18] X. Kong, C. Cai, and J. Hu, "The State-of-the-Art on Framework of Vibration-Based

[20] J. E. Mottershead and M. I. Friswell, "Model Updating In Structural Dynamics: A Survey," J. Sound Vib., vol. 167, no. 2, pp. 347-375, 1993.

[21] Á. Cunha and E. Caetano, "Experimental Modal Analysis of Civil Engineering Structures," Sound Vib., June, pp. 12-20, 2006.

[22] Á. Bautista-De Castro, L. J. Sánchez-Aparicio, L. F. Ramos, J. Sena-Cruz, and D. González-Aguilera, "Integrating geomatic approaches, Operational Modal Analysis, advanced numerical and updating methods to evaluate the current safety conditions of the historical Bôco Bridge," Constr. Build. Mater., vol. 158, pp. 961-984, 2018.

[23] M. Brehm, V. Zabel, and C. Bucher, "An automatic mode pairing strategy using an enhanced modal assurance criterion based on modal strain energies," J. Sound Vib., vol. 329 , no. 25 , pp. 5375-5392, 2010.

[24] G. Osmancikli, A. Bayraktar, T. Türker, Ş. Uçak, and A. Mosallam, "Finite element model calibration of precast structures using ambient vibrations," Constr. Build. Mater., vol. 93, pp. 10-21, 2015.

[25] K. A. T. L. Kodikara, T. H. T. Chan, T. Nguyen, and D. P. Thambiratnam, "Model 
updating of real structures with ambient vibration data," J. Civ. Struct. Heal. Monit., vol. 6 , no. 3, pp. 329-341, 2016.

[26] S. Ivorra, V. Brotóns, D. Foti, M.A. Diaferio, "Preliminary approach of dynamic identification of slender buildings by neural networks," Int. J. Non-lin. Mech. vol. 80, pp. 183-189, 2016.

[27] P. G. Bakir, E. Reynders, and G. De Roeck, "Sensitivity-based finite element model updating using constrained optimization with a trust region algorithm," J. Sound Vib., vol. 305, pp. 211-225, 2007.

[28] S. Ivorra, F. J. Pallares, and J. M. Adam, "Dynamic behaviour of a modern bell tower. A case study,” Eng. Struct., vol. 31, pp. 1085-1092, 2009.

[29] A. Cabboi, C. Gentile, and A. Saisi, "From continuous vibration monitoring to FEMbased damage assessment: Application on a stone-masonry tower," Constr. Build. Mater., vol. 156, pp. 252-265, 2017.

[30] P. Pachón, V. Compán, E. Rodríguez-Mayorga, and A. Sáez, “Control of structural intervention in the area of the Roman Theatre of Cadiz (Spain) by using nondestructive techniques," Constr. Build. Mater., vol. 101, pp. 572-583, 2015.

[31] T. Marwala, Finite Element Model Updating Using Computional Intelligence Techniques. Springer-Verlag, London, Dordretch, Heidelberg, New York, 2010.

[32] J. L. Zapico, M. P. González, M. I. Friswell, C. A. Taylor, and A. J. Crewe, "Finite element model updating of a small scale bridge," J. Sound Vib., vol. 268, no. 5, pp. 993-1012, 2003.

[33] L. Facchini, M. Betti, P. Biagini, "Neural network based modal identification of structural systems through output-only measurement," Comput. Struct., vol. 138, pp. 183-194, 2014.

[34] M. Betti, L. Facchini, P. Biagini, "Damage detection on a three-storey steel frame 
using artificial neural networks and genetic algorithms," Meccanica, vol. 50, no. 3, pp. 875-886, 2015.

[35] D. Jung, C. Kim, "Finite element updating on small-scale bridge model using the hybrid genetic algorithm," Struct. Infrastruct. Eng., vol. 9, no. 5, pp. 481-495, 2013.

[36] ASTM C215-14, Standard Test Method for Fundamental Transverse, Longitudinal, and Torsional Resonant Frequencies of Concrete, ASTM International, West Conshohocken, PA, 2014.

[37] D. Ewins, Modal testing: theory and practice. Second Edition, Research Studies Press, Baldock, Hertfordshire, England, 1995.

[38] R. J. Allemang and D. L. Brown, "A complete review of the complex mode indicator function (CMIF) with applications," in Proc. Int. Conf. Noise Vib. Eng. (ISMA2006), 2006, pp. 3209-3246.

[39] O. Døssing, "Structural Testing. Part 2: Modal Analysis and Simulation." Brüel \& Kjaer, Naerum (Denmark), March, 1988.

[40] H. Takabatake, "Effect of Dead Loads on Natural Frequencies of Beams," J. Struct. Eng., vol. 117, no. 4, pp. 1039-1052, 1991.

[41] S. Zhou and X. Zhu, "Analysis of effect of dead loads on natural frequencies of beams using finite-element techniques," J. Struct. Eng., vol. 122, no. 5, pp. 512-516, 1996.

[42] P. Lundqvist and N. Rydén, "Acoustoelastic effects on the resonance frequencies of prestressed concrete beams - Short-term measurements," NDT E Int., vol. 50, pp. 3641, 2012.

[43] C. Payan, V. Garnier, J. Moysan, and P. A. Johnson, "Determination of third order elastic constants in a complex solid applying coda wave interferometry," Appl. Phys. Lett., vol. 94, no. 1, p. 11904, 2009. 
[44] R. J. Allemang and D. L. Brown, "A correlation coefficient for modal vector analysis," First Int. Modal Anal. Conf., pp. 110-116, 1982.

[45] R. H. Myers and D. C. Montgomery, Response surface methodology: process and product optimization using designed experiments. Wiley, 1995.

[46] L. P. Khoo and C. H. Chen, "Integration of Response Surface Methodology with Genetic Algorithms," Int. J. Adv. Manuf. Technol., vol. 18, no. 7, pp. 483-489, 2001.

[47] J. N. Eiras, J. S. Popovics, M. V. Borrachero, J. Monzó, and J. Payá, “The effects of moisture and micro-structural modifications in drying mortars on vibration-based NDT methods," Constr. Build. Mater., vol. 94, pp. 565-571, 2015.

[48] J. B. Watchman, W. E. Tefet, D. G. Lam, and C. S. Apstein, "Exponential Temperature Dependance of Young's Modulus for Several Oxides," Phys. Rev., vol. 122, no. 6, pp. 1754-1759, 1961.

[49] S. N. Shoukry, G. W. William, M. Y. Riad, and B. Downie, "Effect of moisture and temperature on the mechanical properties of concrete," Constr. Build. Mater., vol. 25, no. 2, pp. 688-696, 2011.

[50] H. Sohn, "Effects of environmental and operational variability on structural health monitoring," Philos. Trans. R. Soc. A Math. Phys. Eng. Sci., vol. 365, no. 1851, pp. 539-560, 2007.

[51] C. Boutin, S. Hans, E. Ibraim, and P. Roussillon, "In situ experiments and seismic analysis of existing buildings. Part I: Experimental investigations," Earthq. Eng. Struct. Dyn., vol. 34, no. 12, pp. 1531-1546, 2005.

[52] A. De la Foye, "Development of a mechanical device meant to excite buildings slated for demolition," in 16th European Conference on Earthquake Engineering, 2017.

[53] C. R. Farrar and K. Worden, Structural Health Monitoring. A Machine Learning 
Perspective. John Wiley \& Sons, Ltd, 2013.

631

632

633

634 